\title{
Bridging the Gap
}

\section{A Collaborative Approach to Health Information Management and Informatics Education}

A.D. Dorsey ${ }^{1}$; K. Clements'; R.L. Garrie'; S.H. Houser'; E.S Berner ${ }^{1}$

${ }^{1}$ The University of Alabama at Birmingham, Health Services Administration, Birmingham, Alabama, United States

\section{Keywords}

Health informatics education, health information management education, comprehensive exam

\section{Summary}

Background: Health Information Management (HIM) and Health Informatics (HI) were very separate professions when they were first formed. However, with the increasing adoption of electronic health records, the interests of the two fields have become more aligned.

Objectives: To describe the evolution of a joint master's program in health informatics(HI) and health information management (HIM)

Methods: After analyzing workforce needs, and reviewing both CAHIIM accreditation requirements and existing curricular offerings in separate programs in HIM and $\mathrm{HI}$, a joint program was developed.

Results: An HI master's program with a core curriculum for all students and tracks in Data AnaIytics, User Experience and Advanced Practice HIM was developed. A model for a comprehensive examination, based on the CAHIIM competencies, to be administered prior to and after the core curriculum was also developed.

Conclusions: A core and track curriculum that incorporates HIM education as part of the Master of Science of Health Informatics provides a feasible roadmap for the future as HIM and HI become more closely aligned.

\section{Correspondence to:}

Amanda D. Dorsey, MSHI, FHIMSS

1705 University Blvd.

SHP Building \#590K

Birmingham, AL 35294

Email: adorsey@uab.edu

\section{Appl Clin Inform 2015; 6: 211-223}

http://dx.doi.org/10.4338/ACl-2014-09-RA-0083

received: September 23, 2014

accepted: February 22, 2015

published: April, 1, 2015

Citation: Dorsey AD, Clements K, Garrie RL, Houser $\mathrm{SH}$, Berner ES. Bridging the gap - a collaborative ppproach to health information management and informatics education. Appl Clin Inf 2015; 6: 211-223 http://dx.doi.org/10.4338/ACI-2014-09-RA-0083 


\section{Background}

While initially separate and quite different professions, the Health Information Management (HIM) and informatics communities have increasingly found common ground in terms of professional interests, research foci, and public policy activities. The profession of health information management in this country has had a long history, with its foundation in the management of paper medical records. The immediate predecessor of the American Health Information Management Association (AHIMA) was the American Medical Record Association, which had evolved from earlier organizations. It became AHIMA in the early 1990s as their interest broadened from medical records to management of health information in a variety of media. An accrediting body, the Commission on Accreditation for Health Informatics and Information Management Education (CAHIIM) [1], originally associated with AHIMA, was established to approve curricula for preparation of HIM credentials at multiple levels.

Beginning in the 1960s, the informatics professionals' early focus was on computer applications in medicine. Internationally in 1967, a technical committee of the International Federation of Information Processing (IFIP) led to the evolution of a fully independent body, the International Medical Informatics Association, which acts as a bridge organization that provides leadership and expertise in health and bio-informatics [2]. IMIA would play a role in the development of educational standards and competencies for health and bio-informatics for decades to come. By the early 1990's the American Medical Informatics Association (AMIA) was formed as a consolidation of several other medical informatics groups. Informatics training programs began in the 1970s and the National Library of Medicine (NLM) training grants are still a major funding source for informatics education [3]. With the growing recognition of the importance of electronic health records, the development of the clinical informatics subspecialty was accomplished in 2013, with fellowship programs planned for the future [4-5].

The two professional associations, AHIMA and AMIA, initially found common ground around the HIPAA legislation in the 1990s and later had a common interest in workforce development [6]. With the Health Information Technology for Economic and Clinical Health (HITECH) Act leading to increased adoption of electronic health records(EHR), it was clear that those who considered themselves HIM professionals and those who considered themselves informaticians were both a needed part of the workforce to foster the appropriate utilization of electronic health records and other forms of health information technology. It was also clear that there was overlap, although not complete, in their skills and job responsibilities as well, in this new era. In part a reflection of the similarities in the two fields, CAHIIM has been collaborating with AMIA on developing accreditation standards for both HIM and Informatics.

Despite the growing overlap of interests and needed skills however, the HIM and Informatics education programs have, for the most part, remained separate. In part, this may be because most of the HIM programs have traditionally been at the associate degree and undergraduate level, and most of the informatics programs are at the master's, $\mathrm{PhD}$, and post-doctoral level. With the need for a larger informatics and HIM workforce, there have been a growing number of programs of each type at the master's level, but even most of those programs have remained separate, despite the fact that there are many skills in common. And more importantly, both HIM and informatics professionals will be working together as part of the teams responsible for development and management of electronic health records, increasing the need for inter-professional education preparation. In this article we describe a master's education program where there is both common and unique training for HIM and informatics professionals.

\section{Historical Overview of MSHI \& BSHIM Programs}

The UAB BSHIM Program began in 1972 and after obtaining approval from the accrediting body, the Committee on Allied Health Education and Accreditation (CAHEA), was accredited in 1974. As healthcare technology and services impacted the documentation in medical records, the curriculum reflected the professional body of knowledge associated with health information practice. The BSHIM Program has continued to maintain program accreditation from CAHIIM. The BSHIM Program was offered in an online format beginning in 1999 through a learning management system 
and in May of 2014, graduated its 40th cohort of HIM students. To attract a wider audience, the HIM Program was also offered in a part-time format to address the growing population of adult and working students who wished to complete their bachelor's degree.

In 1989, with the growing need for leaders in the area of health information technology and information management, a proposal for a graduate program that prepares senior level managers in the areas of strategy, management and implementation of technology in a healthcare setting was introduced. The competencies for the program were derived from a study of the roles and functions of chief information officers [7]. Learning philosophies including self-directed and team-based learning, case-based learning, and peer learning formed the instructional approach. In addition, as others have since noted, we felt that the educational program should include both classroom learning and experience in practice [8]. In addition, we have adopted the practitioner-teacher model in our approach. The practitioner-teacher model has a long history in health professions education, with students learning during their clinical rotations from practitioners in their field. In the non-clinical disciplines, there has also been an emphasis for at least 20 years for involving practitioners in the teaching and evaluation process [9]. To that end, students had required applied projects and internships and we also involved practitioners in the field as instructors, mentors and members of our advisory board.

The need for trained individuals with specific expertise in healthcare IT applications, both departmental - such as laboratory, radiology, emergency information systems - and enterprise wide (master patient index) was also being espoused by AHIMA. Healthcare organizations needed to formulate a migration strategy to move from paper-based medical records to the sophisticated and complex electronic medical records, and given their backgrounds in managing information, HIM professionals were positioned nicely to assume these future management roles. The program goals outlined in the proposal for a new graduate program were also aligned with some of the medical informatics training programs, which focused on the development of applications that could be used in actual clinical care.

The original title of the master's degree was a Master of Science in Health Information Management (MSHIM), which corresponded with the educational goals of AHIMA at the time, which recognized that HIM professionals would need more academic preparation to assume the leadership roles of the future. The newly created master's program was slightly ahead of where most HIM programs were focusing, which was on awarding of undergraduate degrees. The name was changed several years later to the Master of Science in Health Informatics (MSHI) and accepted students with HIM and a variety of other backgrounds.

Based on our surveys of graduating students, we found that most graduates of the program achieve some sort of management position within five years of graduation, and many move on to senior or executive level management positions in healthcare IT organizations.

\section{Methods}

\section{HIM Advanced Practice Track creates Core/Track model}

While the two programs (BSHIM and MSHI) programs peacefully coexisted for a few decades, a number of compelling forces warranted moving the undergraduate BSHIM program to a graduate level. BSHIM undergraduate programs around the country added topics related to health information technology into their curriculum to enhance health informatics and information technology (HIT) knowledge and skills to meet new AHIMA entry level professional competencies. In the practice community, HIM professionals in management positions were working closely with information systems' departments in their health care organizations on the transition to electronic health records. AHIMA's Vision 2016 called for "HIM academic programs to prepare the future HIM professionals for tomorrow's health care environment by developing and promoting graduate education to generate more advanced practitioners" [10]. Locally, UAB's School of Health Profession's strategic plan supported transitioning undergraduate-level curricula to the graduate level. The BSHIM faculty opted to move forward and develop a graduate track for health information management. 
The MSHI Program addressed many of the subject areas in the domains related to health information systems and provided an opportunity for Health Informatics and HIM faculty to work closely together on a curriculum that would meet the AHIMA 2009 HIM Master's Degree Competencies. While different in some aspects, the two programs shared fundamental course requirements related to HIT. In order to identify what became known as the "Health Informatics Core Courses", a grid technique was used to plot the HI courses using the AHIMA domains and subdomains by comparing learning objectives from each of the HI course syllabi to the domain and subdomain subject matter. Courses were then identified and selected for "HI core courses" based on the extent of coverage of subject matter from the domains and subdomains. These were then revised to map to the newly created CAHIIM Facets and Curricular Components for graduate programs in Health Informatics.

A number of professional groups have developed competencies and accreditation standards in informatics [11-14]. There is some overlap of competencies from the different organizations and overlap with our curriculum as well. In fact, previous research examining the match of the MSHI curriculum to both the International Medical Informatics Association competencies and the CPHIMS competencies, found a closer match to the more applied CPHIMS competencies [15]. However, because CAHIIM accredits masters programs in both Health Informatics and Health Information Management, we felt that mapping the curriculum to the CAHIIM competencies[1] in preparation for seeking CAHIIM accreditation was most appropriate for our program.

The HIM Track was developed in 2009, and was designed to prepare graduates with advanced practice skills in a rapidly evolving electronic health care environment. It is offered in an online format with two, three day residential (on-campus) requirements per year, where students interact with their faculty members, their student cohort, alumni and a wide variety of guest speakers and subject matter experts. Applicants are recruited from practicing credentialed Registered Health Information Administrators (RHIA) or Registered Health Information Technologists (RHIT) with undergraduate degrees. Candidates are required to have a minimum of three (3) years of working experience in HIM.

With the success of the new HIM track and several monumental changes in the national health IT landscape, we began to reevaluate the future of both the delivery and the content of the program. The core curriculum was shaped by the requirements of CAHIIM, the main accrediting body for health informatics masters programs. We employ a variety of content delivery methods including asynchronous and synchronous online courses, site visits, and hands-on projects. Our online courses are guided by accepted standards for online courses [16]. Our decisions to focus on data analytics and user experience in addition to the basic core competencies that were required by CAHIIM, were shaped in part by the advice of our advisory committee who are experts in the industry, but also by current trends in national data. The HITECH Act of 2009, part of the American Reinvestment and Recovery Act (ARRA) of 2009 [17], was one of the most sweeping pieces of healthcare legislation to be passed in decades. It significantly reduced many long-standing barriers to adoption of electronic health records (EHRs) by providing financial incentives from the Centers for Medicare and Medicaid Services (CMS) to eligible professionals (physicians, DOs, NPs, PAs) who purchase and use certified EHRs in a meaningful way ("Meaningful Use" incentives). In attempting to meet the goals of the HITECH Act (to improve healthcare outcomes, facilitate access to care and simplify care) and to reap the Meaningful Use incentives, providers across the United States adopted EHRs at an unprecedented pace. In their 2014 Report to Congress, ONC reported that 59\% of hospitals and $78 \%$ of office physicians had adopted at least a basic HER [18].

As adoption of EHRs has increased, there have been concerns about the usability of the EHRs that have been adopted [19] as well as the design issues involved in preparing for more patient engagement with their health records that is a part of the later stages of the meaningful use regulations [20-21].

In addition, EHR adoption rates have increased. Bates et al., as well as Simborg et al. note that big data in healthcare will be increasing [21-22] and National Institute of Health (NIH), among others, have recognized the need for more individuals who are equipped to analyze large data sets [23]. In addition, there is increased interest in sharing data across systems for patient-centered outcomes research [24]. The Bureau of Labor Statistics indicated that "a major impediment to the widespread use of big data is the lack of workers with the appropriate training and skills." [24, page 9]. The need 
for preparing informatics students to not only understand these developing areas, but to take a leadership role in them, was a driver for the new directions of our curriculum.

With new, highly-specialized EHRs now in place, providers are not seeking the healthcare IT generalists as they once did; rather, they are looking for individuals who were already well-acquainted with the provider's specific EHR system or for individuals who were skilled at system optimization (user experience) and data analysis. Anecdotal evidence pointed to a slowing pattern in the hiring of our students who graduated shortly after the HITECH Act. After a strategic planning process, our faculty conceded that these two skill sets would drive much of the demand in healthcare for the foreseeable future, so two new tracks in User Experience and Data Analytics were created to ensure our graduates were equipped with these skills. While a formal needs analysis was not conducted, our plans were both informed by, and reviewed by our advisory committee, which included stakeholder representatives from a variety of healthcare settings and organizations.

The new tracks in User Experience and Data Analytics were a nice complement to the existing HIM Advanced Practice Track and presented our program with many exciting and new possibilities. Still, we knew that in order to attain accreditation and ensure a consistent curriculum, we would need to re-align our designated MSHI "core" courses (i.e. the courses that all first year students take together regardless of which track they pursue in their second year) with CAHIIM's three major facets or domains for Health Informatics Graduate Programs. To ensure that we were meeting the CAHIIM facets, we reviewed, in detail, our course content against the CAHIIM requirements and identified areas in our curriculum where there was a direct match and areas where our curriculum did not address the CAHIIM content. As our faculty went through the alignment process, we both added curricular components that we lacked, and deleted curricular components that were either not required by CAHIIM, or no longer a driving force in the informatics industry.

The CAHIIM Curricular Facets for Health Informatics Graduate Program include

1. Information Systems, focusing on "issues such as information systems analysis, design, implementation, management and leadership."

2. Informatics, focusing on the "structure, function and transfer of information, socio-technical aspects of health computing, and human-computer interaction."

3. Information Technology, which focuses on computer networks, database and systems administration, security and programming. A detailed listing of the CAHIIM Facets may be found in the Supplementary Appendix.

The full course sequencing is listed in Tables 1-4 and the sequence of developments is listed in - Table 5.

\section{Results}

\section{Design of New Core/Track Model User Experience Track}

The fields of User Experience and user-centered design concepts are relatively new to healthcare, but have found great success in many other industries, including consumer electronics (Apple Products) and business to business/business-to-consumer transactions (Amazon.com) by employing user-centered design techniques to make a more satisfying experience for the consumer or user of the product. Evidence of such well-designed consumer applications and devices - or „experiences“ - are puzzling to healthcare professionals, who know that more could be done to improve their own experience with technology. The American Medical Association identified eight priorities for improving the usability of electronic health records (EHRs) [26]. These priorities relate to making the healthcare teams' tasks easier, the EHRs more flexible, and increasing patient engagement. Yet most people working in healthcare are unaware that better design and modeling of a technology solution is achievable with the assistance of a user-experience professional. The added value that graduates of this proposed track would bring is in-depth understanding of a complex healthcare delivery system and how technology can support it, not hinder it. 
Implementation of the Healthcare User Experience track within the MSHI Program was designed to integrate the distinct domains of healthcare, social sciences and health informatics and will prepare individuals to become leaders in areas such as healthcare interface design and integration, patient and clinical end-user research, patient/clinician-centered system analysis, patient safety/quality analysis, healthcare IT consulting, healthcare software development, clinical/business analysis. Additionally, the track should promote the practice formal practice of user experience as a discipline to design safer, friendlier and more effective healthcare information systems and address the critical need of provider adoption in healthcare information technology design through end-user research and design best practices.

\section{Data Analytics Track}

The proliferation of information technology to support workers in the healthcare industry has resulted in a massive amount of data being generated. While the data are seen as an organizational asset that can both help determine trends and patterns within patient care delivery and allow consumers to compare health plan performance [27], there are very few individuals trained to extract, combine, manipulate, interpret and display these data [28]. This track would produce graduates who could immediately begin to help healthcare organizations implement data-governed decision-making processes. Beyond that, graduates of this track could assist organizations with developing data governance strategies, data quality, security, access to and policies and processes surrounding data.

The HITECH Act called for the establishment of State Health Information Exchanges (HIE). This requires that individuals be knowledgeable not only about sharing data within a system, but also across healthcare systems. The implications of being able to securely share and analyze appropriate data among providers (with a federally issued National Provider ID) within a state, region, or eventually nation-wide brings great promise to our ability to truly understand topics like population health and bio-surveillance. But the path to creating and sustaining a fully-functioning HIE remains difficult, and requires individuals trained in health information systems and data interoperability.

This level of interoperability, data sharing and data analysis between and among systems is currently understood by only a handful of people within most healthcare organizations. Individual programs in schools within the state of Alabama offered courses in quantitative methods, business intelligence, health-focused classes and computer science, but ours is the only program in the state to offer the combination of these disciplines in a single program or track leading to a master's degree.

In developing the curricula for both the User Experience and Data Analytics tracks, we consulted with practitioners from both of these fields. We also anticipate using these practitioners to either teach or co-teach these track courses for us until we can find suitable full-time faculty with appropriate credentials. Even after recruiting full time faculty, we will continue to utilize the practitioners for input either through guest lectures or as subject matter advisors on student projects.

\section{Implementation Challenges \\ Changes in Recruiting Model}

The new Core/Track model presents many opportunities, and also brings some challenges in recruiting future cohorts. All students will enter into their first year of "core" informatics courses together, regardless of which track they will pursue in their second year. The challenge lies in formulating a strategy for recruiting individuals who have the requisite skill mix to pursue the various tracks. For instance, the Data Analytics track may appear to be an intriguing option to some prospective students, but without appropriate on-the-job training or exposure to the more quantitative nature of data manipulation, these students would not be as successful in that track. Likewise with the User Experience track, students ideally should have had exposure to a full healthcare systems development life-cycle in order to truly understand the complex design decisions required in that track. The plan is for students to be recruited from healthcare organizations that are already in need of data analytics or user experience expertise. In this recruiting model, we would assume more of an academic/industry collaborative partnership, offering an academic solution to problems currently being experienced by healthcare leaders. This approach is advantageous to the organization because it can be used to incentivize and nurture talented employees. 
A fact remains, however, that we did not have a methodological way to identify deficits in the informatics body of knowledge of the students we were recruiting. Because of the variation in the professional and academic backgrounds of the students we recruit, some will come to us with clinical experience (both academic and professional) and still other students will come to us with extensive technological skills. We expect that our peer-to-peer learning model, that is reinforced both in person and in the online classes with team projects and online discussion, will help to bridge the gaps, but we plan to revisit both our recruiting strategy and our prerequisites as we gain experience with the new program.

Because our students are also working professionals and adult learners, it is likely that they will also want to know exactly where their knowledge deficits are so they can correct them. Finally, understanding where these deficits are would be very valuable to faculty, who could, in turn, guide their courses to emphasize or de-emphasize material based on entering students' proficiency with certain curricular areas.

\section{Evaluation}

\section{Development of an assessment model}

Because we expect students to master knowledge as well as skills and attitudes, we have devised different types of evaluation methods. We decided to assess knowledge acquired during the program by means of a pre/post knowledge examination. We assess skills in integrating and applying that knowledge (higher levels of Bloom's taxonomy) by a synthesis project at the end of the program [29]. Given the diversity of our student body and our plans for a new core set of courses, we wanted to develop a process that could be used to guide and evaluate our new curriculum. Since many of the certifying exams for HIM and informatics professionals use multiple choice tests, to assess knowledge we chose to develop a multiple choice assessment process that was based on the facets of the CAHIIM health informatics accreditation model, since that model was also the basis of the curriculum [1]. The plan is for students to take the exam just prior to beginning the program and again after completing their core coursework.

We chose a pre/post model for several of reasons. First of all, the regional accrediting body for UAB, the Southern Association of Colleges and Schools (SACS), expected to see a post-course evaluation. A pre/post model would allow us to demonstrate mastery as well as improvement. Secondly, the results will help reassure our alumni and future employers of the strength and appropriateness of the program's curriculum. This was the first year of the matriculation exam, and we expect that we will assess and refine the content of the exam annually to capture more specific data about the outcomes.

The initial matriculation exam is used to identify gaps in student preparation, both for the individuals and for the instructors. If gaps are widespread this can inform instructors on where there may need to be special emphasis in the curriculum. Because many of our students are experienced professionals in the health IT or HIM fields, we anticipated that their initial scores on the exam might be fairly high. The aim of the curriculum is to bring all students to a level of mastery of the core content. In this way, at the end of the core, the exam will serve as an assessment of the curriculum as well as the students.

Our test development procedures followed recommended test development strategies that have been used by large testing organizations for decades [30]. These procedures include mapping the questions to competencies/content/objectives, doing an item analysis to determine the psychometric characteristics of the test, and revising the test if needed pending review.

To develop the initial exam, a core test development team (ADD, ESB, RLG) began by reviewing the CAHIIM competencies described in the Appendix and reviewing test questions to which we had access. These included the questions from the ONC health IT curriculum [31] as well as questions from test-banks contained in selected textbooks being used in the curriculum. Because Facet 1 of the CAHIIM competencies is so comprehensive and contains content similar to that in Facets 2 and 3 , the majority (roughly 70\%) of the questions on the exam were from that facet. For instance, Facet 1 contains a curricular component which addresses the "use of healthcare terminologies, vocabularies and classification systems" while Facet 2 contains a curricular component which addresses the "development of healthcare terminologies, vocabularies and ontologies". Although we started with 
these questions, many of them were adapted for our purposes. The intent is to build, over time, an item bank of new questions that can be used to develop sets of parallel examinations. The questions were mapped to the CAHIIM competencies, reviewed, selected and modified by the test development team and assembled into the final test.

\section{Program Evaluation}

A class of sixteen students was admitted in the fall of 2014. Seventy percent (70\%) were female, and all but two have healthcare-industry experience. The average age of the cohort is 35 and the years of work experience range from three to twenty-five. The initial exam of 155 questions was given to all students during their orientation session for the program. Psychometric data on the test questions were collected (reliability, difficulty and discrimination indices). The exam had high reliability (Cronbach's $\alpha=0.91$ ) [32] and the scores ranged from $32 \%$ to $80 \%$, with a mean score of $58 \%$. In addition to the sub-scores for the three different facets, smaller groups of questions were also identified for other topics that are specific to the UAB curriculum.

Following standard test development practices [30] poorly performing questions were eliminated $(n=7$ out of 155 , spread across all facets), the exam was rescored and students were given their scores. In addition to their scores, the students were given an outline of where particular curricular components within the CAHIIM facets map to our curriculum so that they may focus on the areas where they performed the weakest. The data from the initial test as a whole will also be used to inform the faculty of the content areas where students performed sub-optimally, as well as where students performed exceptionally well.

For comparison purposes, we will administer the same test (minus the poorly performing questions) at the end of the summer semester, 2015, when the students will have completed the core health informatics content. The second test will be administered to determine if completion of our curriculum improves the overall and individual scores of the students. During the next year, the health informatics program faculty will develop a new exam that contains a bank of new questions. Although we are mainly using this examination for curricular planning, for the post-test, the faculty will work with the Associate Dean of the School of Health Professions to determine an appropriate "passing" score. Our expectations are that this will be a criterion-based mastery exam, but we will explore a variety of methods that are commonly used on certifying exams to determine a passing score [33].

The scores will also officially become reporting measures for programmatic and student learning outcomes under SACS requirements [34]. Finally, the faculty will determine a process of how to handle students who do not achieve a passing score.

In addition to using the examination to evaluate the students and the curriculum, to assess both attitudes and ability to apply that knowledge in practice we plan to use job placement rates and graduate and employer surveys as measures of success. We also anticipate that we will make modifications on our curriculum based on the results of those surveys.

\section{Conclusion}

We have demonstrated a method for linking health informatics and health information management curricula that provides inter-professional education during the core courses as well as unique tracks for HIM, User Experience, and Data Analytics specialties. We also developed a comprehensive examination program based on the CAHIIM competencies that serves both assessment and curriculum development goals. The results from the exam have provided more meaningful insight into forming appropriate and measurable student learning and programmatic outcomes for students with varying professional and academic backgrounds. It is our hope that the "roadmap" (the linking of their deficiencies on the CAHIIM facets that correspond with courses in our curriculum) will help students focus on their particular areas of deficiency. We also believe that the pre and post testing will continue to inform our faculty of the knowledge level of future incoming cohorts and help us refine the delivery of content in our curriculum.

Graduates of Health Informatics and HIM programs have long been in positions to help with organizational aspects of EHRs, but must now focus on what opportunities are available in the post- 
HITECH era, and this will have implications for our ongoing curriculum and faculty development. We have emerged from an era of merely having to manage systems, data and information within our own organizations, to working toward achieving interoperability with information systems and organizations outside of our own. Other forces, such as the rapid proliferation of technology, healthcare consumerism and the political landscape will also inevitably shape our curriculum in the years to come For those of us in academia, it means we will need to adapt our curricula in a manner and pace that we haven't seen in years past. For our future students, it means that there is no foreseeable shortage of work for those interested in Health Informatics and Health Information Management careers.

\section{Clinical Relevance Statement}

The results of having created and administered this comprehensive exam has relevance for practitioners because it provides a direct map between an informatics-specific body of knowledge contained in the CAHIIM accreditation standards and our curriculum. This is valuable for future employers of our students who may wish to validate the depth of content in our curriculum and to future cohorts of students, so that they may personally demonstrate measurable learning outcomes as a result of their matriculation.

\section{Human Subjects}

This is not a research study and Human Subjects review is not needed.

\section{Conflict of Interest Statement}

The authors of this article certify that they do not have any affiliations with or involvement in any organization or entity with financial or non-financial interest in the subject matter or materials discussed in this manuscript. 
Table 1 Year 1 - MSHI Core (All Students)

\begin{tabular}{l|l}
\hline Fall & - HI 640 Introduction to Health Informatics and the US Healthcare Delivery System \\
- HI 600 Analysis \& Design of Information Systems in Healthcare
\end{tabular}

Table 2 Year 2 - User Experience Track

\begin{tabular}{|l|l|}
\hline Fall & - HI 650 Foundations of Healthcare User-Based Design \\
& - HI 651 Foundations of Healthcare User-Based Research \\
- HI 686 Leadership Theory
\end{tabular}

Table 3 Year 2-Data Analytics Track

\begin{tabular}{l|l}
\hline Fall & - HI 660 Healthcare Requirements Analysis \\
& - HI 661 Advanced Database Design and SQL for Healthcare \\
- HI 686 - Leadership Theory \\
\hline Spring & - HI 662 Healthcare Business Intelligence \\
& - HI 632 Quantitative Methods for Health Informatics \\
- HI 687 Leadership Development
\end{tabular}

Table 4 Year 2 - HIM Advanced Practice Track

\begin{tabular}{l|l}
\hline Fall & - HIM 615 Development of the Electronic Health Record \\
& HIM 650 Research Methods for HIM Practice \\
- HI 686 Leadership Theory \\
\hline Spring & - HIM 665 Health Data Analytics for Performance Improvement \\
- HIM 680 Applied Project I.HI 687 Leadership Development \\
\hline Summer & - HIM 681 Applied Project II \\
- HIM 682 Seminar: Implementation Strategies for the EHR \\
- HI 688 Leadership Advocacy
\end{tabular}


Table 5 Timeline of Developments in Health Information Management and Health Informatics Programs

\begin{tabular}{|l|l|}
\hline Development & Year \\
\hline BSHIM Program founded & 1972 \\
\hline BSHIM Program accredited & 1974 \\
\hline Plan for graduate HIM program & 1989 \\
\hline MSHIM program founded & 1991 \\
\hline MSHIM program changed to MSHI & 1995 \\
\hline MSHI adds advanced practice HIM track & 2009 \\
\hline BSHIM admits its last cohort & 2013 \\
\hline Core/track model with HIM, User Experience, and Data Analytics tracks begun & 2014 \\
\hline
\end{tabular}




\section{References}

1. Commission on Accreditation for Health Informatics and Health Information Management Education. http://cahiim.org/Files-Standards/2012_HI_Masters_Stndrds_elec.pdf Accessed 9/19/2014

2. International Medical Informatics Association. http://www.imia-medinfo.org/new2/node/1 Accessed $02 / 09 / 2015$

3. Florance V. Training for informatics research careers: History of extramural informatics training at the National Library of Medicine. In Berner ES. Informatics Education in Healthcare: Lessons Learned. London, UK: Springer, Inc., 1990, pp. 27-42.

4. Gardner RM, Overhage JM, Steen EB, Munger BS, Holmes JH, Williamson JJ, Detmer DE; AMIA Board of Directors. J Am Med Inform Assoc 2009; 16(2): 153-157.

5. Safran C, Shabot MM, Munger BS, Holmes JH, Steen EB, Lumpkin JR, Detmer DE; AMIA Board of Directors. Program requirements for fellowship education in the subspecialty of clinical informatics. J Am Med Inform Assoc 2009; 16(2): 158-166.

6. American Health Information Management Association and American Medical Informatics Association. Joint Workforce Task Force. Health information management and informatics core competencies for individuals working with electronic health records. Available at: http://library.ahima.org/xpedio/groups/public/documents/ahima/bok1_040723.pdf Accessed 9/16/2014.

7. Johns ML. The development of a graduate program in health information management. Methods Inf Med 1994; 33(3): 278-281.

8. Bates M, Black C, Blair R, Davis L, Ingram S, Lane D et al. Perceptions of health information management educational and practice experiences. Perspect Health Inf Manag 2014, 11(Summer):1d.

9. Montgomery LD, Enzbrenner LR, Lerner WM. The practitioner-teacher model revisited. J Health Adm Educ 1991; 9(1): 9-24.

10. American Health Information Management Association. Vision 2016: A Blueprint for Quality Education in Health Information Management. September 2007. http:/library.ahima.org/xpedio/groups/public/ documents/ahima/bok1_035517.pdf

11. Kulikowski CA, Shortliffe EH, Currie LM, Elkin PL, Hunter LE, Johnson TR et al. AMIA Board white paper: definition of biomedical informatics and specification of core competencies for graduate education in the discipline. J Am Med Inform Assoc 2012; 19(6): 931-938.

12. Mantas J, Ammenwerth E, Demiris G, Hasman A, Haux R, Hersh W et al. Recommendations of the International Medical Informatics Association (IMIA) on Education in Biomedical and Health Informatics. First Revision. Methods Inf Med 2010; 49(2): 105-120.

13. Hasman A, Mantas J IMIA accreditation of health informatics programs. Healthc Inform Res 2013; 19(3): $151-161$

14. Covvey HD, Zitner D, Bernstein R. Pointing the way: competencies and curricula in health informatics, 2001. Available at: http://www.nihi.ca/nihi/ir/Pointing\%20the\%20Way\%20MASTER\%20Docu ment\%20Version\%201\%20Final.pdf. Accessed 10/31/2014.

15. Moore, RA and Berner, ES. Assessing graduate programs for healthcare information management (HIM/T) executives. International Journal of Medical Informatics 2004; 73(2): 195-203.

16. Quality Matters. A national benchmark for online course design. Available from: https://www.qualitym atters.org/ Accessed 2/2/2015.

17. Health Information Technology for Economic and Clinical Health (HITECH) Act, Title XIII of Division A and Title IV of Division B of theAmerican Recovery and Reinvestment Act of 2009 (ARRA), Pub. L. No. $111-5,123$ Stat. 226 (Feb. 17, 2009), codified at 42 U.S.C. $\$ \$ 300$ jj et seq.; $\$ \$ 17901$ et seq.

18. The Office of the National Coordinator for Health Information Technology (ONC), Office of the Secretary, U.S. Department of Health and Human Services [Internet]. Report to congress. Update on the adoption of health information technology and related efforts to facilitate the electronic use and exchange of health information. October 2014. Available from: http://www.healthit.gov/sites/default/files/rtc_adop tion_and_exchange9302014.pdf. Accessed 2/2/2015

19. Middleton B, Bloomrosen M, Dente MA,et al. Enhancing patient safety and quality of care by improving the usability of electronic health record systems: recommendations from AMIA. J Am Med Inform Assoc 2013; 20: e2-e8.

20. Blumenthal D, Tavenner M. The "meaningful use" regulation for electronic health records. N Engl J Med 2010; 363(6): 501-504.

21.Simborg DW, Detmer DE, Berner ES. The wave has finally broken: Now what? J Am Med Inform Assoc 2013; 20: e21-e25.

22. Bates DW, Saria S, Ohno-Machado L, Shah A, Escobar G. Big data in health care: using analytics to identify and manage high-risk and high-cost patients. Health Aff (Millwood) 2014; 33(7): 1123-1131. 
23. Data and Information Working Group. Draft Report to The Advisory Committee to the Director. National Institutes of Health, June 15, 2012. Available at: http://acd.od.nih.gov/Data\%20and\%20Informatics\%20Working\%20Group\%20Report.pdf).

24. Collins FS, Hudson KL, Briggs JP, Lauer MS. PCORnet: turning a dream into reality. J Am Med Inform Assoc 2014; 21(4): 576-577.

25. Royster, S; Working with big data. Occupational Outlook Quarterly. 2013 Fall: 2-10. Available from: http://www.bls.gov/careeroutlook/2013/fall/art01.pdf . Accessed 2/2/2015.

26. American Medical Association. AMA calls for design overhaul of electronic health records to improve usability. Sept. 16, 2014. Available at: http://www.ama-assn.org/ama/pub/news/news/2014/2014-09-16-sol utions-to-ehr-systems.page. Accessed 9/22/2014.

27. National Center for Quality Assurance. Healthcare effectiveness data and information set. http://www. ncqa.org/HEDISQualityMeasurement.aspx. Accessed 9/22/2014

28. Manyika J, Chui M, Brown B, Bughin J, Dobbs R, Roxburgh C, Byers AH. McKinsey Global Institute. Big data: the next frontier for innovation, competition, and productivity. May 2011. Available at: http://www. mckinsey.com/insights/business_technology/big_data_the_next_frontier_for_innovation. Accessed $9 / 22 / 2014$

29.Vanderbilt University Center for Teaching [Internet]. Bloom's Taxonomy. [cited 2015 Feb 2]. Available at: http://cft.vanderbilt.edu/guides-sub-pages/blooms-taxonomy/. Accessed 2/2/2015.

30.Downing, SM. Twelve Steps for Effective Test Development. In: Downing SM, Haladyna TM, editors. Handbook of test development. Mahwah, NJ: Lawrence Erlbaum Associates; 2006. p. 3-25.

31. Mohan V, Abbott P, Acteson S, Berner ES, Devlin C, Hammond WE, Kukafka R, Hersh W. Design and evaluation of the ONC health information technology curriculum. J Am Med Inform Assoc 2014; 21: 509-516.

32. Cronbach L. Coefficient alpha and the internal structure of tests. Psychometrika 1951; 16(3): 297-334.

33.Impara JC, Plake BS. Standard setting: an alternative approach. J Educ Meas 1997; 34 (4): 353-66.

34. Southern Association of Colleges and Schools. Available at: http://www.sacs.org/ Accessed 9/19/2014. 